\title{
Seminar on male involvement in reproductive health in Egypt: Summary of research findings and future directions
}

Nahla G. Abdel-Tawab

Population Council

Follow this and additional works at: https://knowledgecommons.popcouncil.org/departments_sbsr-rh

Part of the Demography, Population, and Ecology Commons, Family, Life Course, and Society Commons, Health Services Research Commons, and the International Public Health Commons How does access to this work benefit you? Let us know!

\section{Recommended Citation}

Abdel-Tawab, Nahla G. 1998. "Seminar on male involvement in reproductive health in Egypt: Summary of research findings and future directions," Asia and Near East OR/TA Project Final Report. Alexandria, Egypt: Population Council. 
Seminar On Male Involvement In

Reproductive Health In Egypt:

Summary Of Research Findings

And Future Directions

May 4-5, 1998

Alexandria, Egypt

Final Report

June 1998 
Population Council

Asia and Near East Operations Research and Technical Assistance Project

\section{SEMINAR ON MALE INVOLVEMENT IN REPRODUCTIVE HEALTH IN EGYPT: SUMMARY OF RESEARCH FINDINGS AND FUTURE DIRECTIONS}

May 4-5, 1998

Alexandria, Egypt

Report prepared by: Nahla Abdel-Tawab

In-House Project \# 03845

This project was conducted with support from the Population Council's Asia and Near East Operations Research and Technical Assistance (ANE OR/TA) Project. The ANE OR/TA Project is funded by the US Agency for International Development, Office of Population under contract No. DPE-C-00-90-0002-10 and DPE-3030-Q-00-0023-00 Strategies for Improving Family Planning Service Delivery. 
Seminar on Male Involvement in Reproductive Health in Egypt: Summary of Research Findings and Future Directions

May 4-5, 1998,

Alexandria, Egypt 


\section{SEMINAR ORGANIZATION TEAM}

Seminar Coordinator:

Nahla Abdel-Tawab

Country Fellow, ANE OR/TA Project

Organizing Committee:

Dale Huntington

Deputy Director, ANE OR/TA Project

Laila Nawar Host Country Advisor, ANE OR/TA Project

Maali El-Guemei Egypt Program Manager, AVSC Int'l Hassan El-Gebaly Executive Director, SDP

Publications \& Print Materials

Sahar Hegazi

Communications Specialist, ANE OR/TA Project

Logistic Support

Nevine Nazim

Program Administrator, ANE OR/TA Project

Ola Zakaria Secretary, ANE OR/TA Project 


\section{TABLE OF CONTENTS}

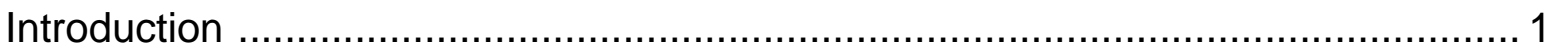

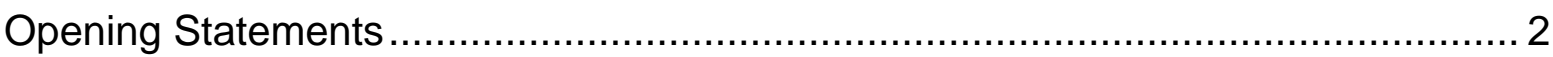

Husband-wife Communication about Family Planning ….................................... 3

Men's Perception of Sexuality / Reproductive Health .......................................... 6

Husbands as Partners in Reproductive Health ................................................... 3

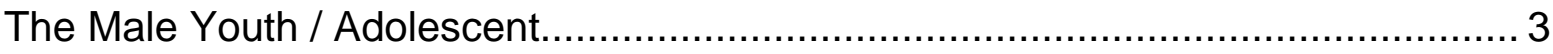

Future Directions in Programs \& Research involving men..................................... 3

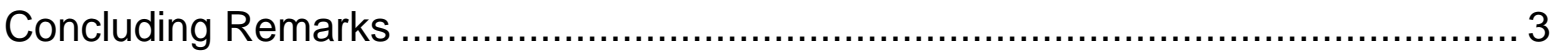

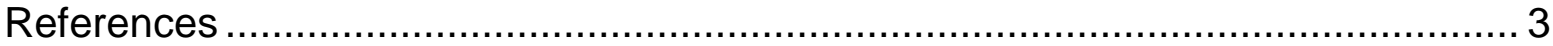

Appendix

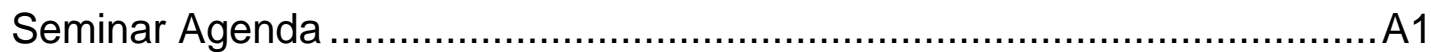

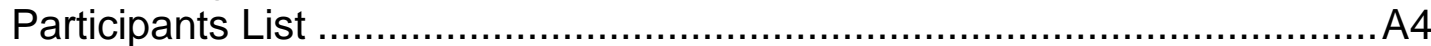

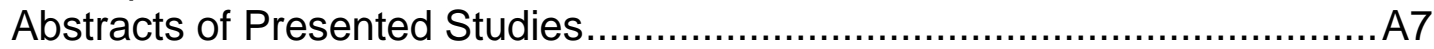




\section{EXECUTIVE SUMMARY}

Interest in involving men in reproductive health matters has been growing in Egypt since the 1994 International Conference on Population and Development. The Men as Partners Inter-Regional Workshop organized by the Agency for Voluntary and Safe Contraception in May of 1997 which was attended by ten participants from Egypt stimulated additional interest in the topic of male involvement. In an effort to coordinate activities to increase male involvement in reproductive health the Population Council's ANE OR/TA Project organized a seminar on "Disseminating results of research on male involvement in reproductive health in Egypt on May 4-5, 1998 in Alexandria, Egypt. The meeting was attended by over 50 participants including key researchers, program managers, policy-makers and donor agencies.

The objectives of the meeting were (1) to present findings of current studies on male involvement in reproductive health care programs in Egypt; (2) to identify policy and program management implications of the male-oriented research; (3) to identify methodological and ethical issues related to conducting research or providing services that involve men; (4) to identify themes for future operations research on male involvement in reproductive health in Egypt.

The two-day meeting included plenary sessions as well as discussion groups. Plenary sessions included presentations of scientific papers followed by a discussion. Breakaway discussion groups discussed programmatic implications of the studies, ethical issues or concerns related to male involvement interventions and identified research gaps that could suggest future studies.

The main themes that were discussed in the meeting were: husband-wife communication and decision-making about family planning / reproductive health, perceptions of sexuality / reproductive health, involving men as partners in reproductive health, reproductive health needs among youth, and future directions in programs and research to enhance male involvement in reproductive health.

There was a general agreement that at present men's involvement in reproductive health was limited: men knew very little about reproductive health issues, and did little to support the reproductive health of their spouses. Participants identified a number of socio-economic and cultural factors that may have contributed to men's limited involvement. Social restrictions around discussions of sex / reproduction were seen as partly responsible for the lack of reproductive health knowledge among youth.

Participants agreed on the need for involving men in reproductive health services for their spouses, providing reproductive health services for men, including youth. In fact it was reported that the MOHP in Egypt is taking several steps in this direction through increasing awareness of service providers regarding the importance of involving men and through changing current standards of practice to take account of the role of husbands in the reproductive health of their spouses. 
Participants suggested the following interventions for increasing male involvement: (1) training of health care providers (both inservice and undergraduate) on how to include husbands in the health care of their spouses, including training on joint counseling, (2) changing the current set-up in family planning clinics and $\mathrm{OB} / \mathrm{GYN}$ wards to allow for the presence of husbands with their wives and to integrate services for men within current services, (3) introducing more information about sexuality / reproductive health issues in school curricula, (4) interventions at the community level to change gender attitudes and to address concerns / misconceptions about male involvement, and (5) raising awareness of policy-makers and stakeholders about the need for providing reproductive health services for men, including youth.

A number of ethical issues in relation to providing services for men and/or including husbands in health care for their spouses were raised by participants. There was a general agreement that services for men must not take away or undermine quality of reproductive health services for women. Also, women should be asked if they want their husband to be involved in their health care so women's autonomy will not be undermined. Services for youth should be provided in a culturally sensitive manner to minimize negative reactions from parents or other stakeholders. Every effort should be made to protect the confidentiality and privacy of youth seeking those services.

Participants believed presented studies helped in shedding light on the current status of male involvement in reproductive health in Egypt. However, the following have been suggested as areas that need to be addressed in future research on men: (1) dynamics of husband-wife decision-making, including strategies for resolving disagreement, (2) men's perceptions of their own sexuality, (3) service needs of men, especially youth; (4) the feasibility and effectiveness of integrating services for men within existing reproductive health services. Also, participants indicated a need for valid measures of some of the concepts related to male involvement and more qualitative research for studying such culturally bound attitudes and behaviors. 


\section{INTRODUCTION}

The 1994 International Conference on Population and Development (ICPD) was an important benchmark in the development of programs to increase male involvement in reproductive health worldwide. The ICPD delegates from 183 countries strongly recommended increasing male access to and involvement in the reproductive health care of their spouses.

During the past few years there has been a number of studies in Egypt that examine men's roles in their wives' reproductive health care. Most of these studies have focused on male involvement with the family planning program. The Ministry of Health and Population (MOHP) has used this research in developing programs to increase husband involvement in family planning services. Efforts are also underway to improve basic reproductive health services for men in MOHP clinics and to establish adequate referral systems for treatment of more advanced cases.

In May of 1997 a team of ten participants from Egypt that included senior MOHP officials, NGO program managers, researchers and journalists participated in the Men As Partners (MAP) workshop that was held in Mombasa, Kenya in May 1997. The meeting, organized by the Agency for Voluntary and Safe Contraception, International examined practical ways for providing services for men and for supporting their constructive involvement in the health of their spouses. The MAP meeting initiated efforts in Egypt to coordinate male involvement activities across sectors and programs.

Among activities to be coordinated was the growing body of research on male involvement in reproductive health in Egypt. As more work in the area of male involvement is expected in Egypt, it is important that researchers and donor agencies become aware of the existing studies, topics covered and main research findings so duplication of work could be avoided. It is also important that policymakers and program managers learn about the results of existing studies so they could use those results in designing more effective policies to increase male involvement in Egypt.

To address the above need, the Population Council's ANE OR/TA Project organized a seminar on "Disseminating Results of Research on Male Involvement in Reproductive Health in Egypt" held on May 4-5, 1998 in Alexandria, Egypt. 
Participants in the meeting included key researchers, program managers, policymakers and donors. A list of participants who attended the seminar and their affiliation is attached in the Appendices. Four main objectives guided the development of the meeting:

- To present findings of current studies on male involvement in reproductive health care programs in Egypt;

- To identify policy and program management implications of the maleoriented research;

- To identify methodological and ethical issues related to conducting research or providing services that involve men;

- To identify themes for future operations research on male involvement in reproductive health in Egypt.

The two-day meeting included plenary sessions as well as discussion groups. The main themes that were discussed in the meeting were: husband-wife communication and decision-making about family planning / reproductive health, perceptions of sexuality, involving men as partners in reproductive health, reproductive health needs of adolescents, and future directions in programs and research to increase male involvement in reproductive health. Plenary sessions included presentations of scientific papers and questions and comments from participants. Breakaway discussion groups discussed the programmatic implications of the studies, ethical issues or concerns related to male involvement interventions and identified research gaps that could suggest future studies. This report is a summary of the presentations along with comments and suggestions that were made around each topic. A copy of the seminar agenda and abstracts of the presented studies are attached in the Appendices. 


\section{OPENING STATEMENTS}

The opening panel for the seminar included Dale Huntington, Deputy Director of the Population Council's ANE OR/TA Project, Mahmoud Khedr, first undersecretary at the Ministry of Health and Population in Alexandria, and Richard Martin, Director of the Office of Population at USAID, Cairo. Dale Huntington drew upon the work of Margaret Greene and Ann Biddlecom to describe current approaches to studying men as being "problem-oriented", i.e. the underlying assumption in these studies is that men act as barriers to their spouses' use of family planning / reproductive health services. He emphasized the need to move beyond the "problematic approach" and to study men in their own right and to examine issues as they relate to the social development of the Egyptian male.

Mahmoud Khedr suggested that women have traditionally been the targets of all family planning research as well as programs. He emphasized the need for focusing on men since they are the prime decision-makers in the Egyptian family. $\mathrm{He}$ suggested the need for research to examine the role of men in decisions related to reproductive health and also to examine men's concerns about different family planning methods. He added that programs should encourage husbands' involvement in health services for their spouses.

Richard Martin pointed to the discrepancy between "conventional wisdom" and reality about the role of men in the Egyptian family. The "conventional wisdom" about male roles is usually negative: for example, men beat women; they want many children; they do not support family planning. However, the reality is that the Egyptian family is strong, stable and fathers are devoted and care about their children. According to Martin this suggests a deficiency in the currently used research methods. There is a need to refine current research methods and tools in order to obtain more accurate information about the role of men in the Egyptian family. Also, he identified several areas of research that need to be addressed for a better understanding of that role: discussions between husbands and wives, the concept of the "male ego" and the extent to which it influences husband-wife relations, men's knowledge about reproductive health, sources of information for men, and sources of influence on men's decisions. Future interventions should not be directed at men or women but at the family as a whole. 


\section{HUSBAND-WIFE COMMUNICATION ABOUT FAMIL Y PLANNING}

Studies that were presented in this session examined several aspects related to husband-wife communication about family planning, particularly the dynamics of decision-making, variables associated with increased husband-wife communication, and the effects of husband-wife communication on family planning decision-making.

According to the studies that were presented in the session husbands and wives seldom discuss the use of family planning or the number of children that each wants. Despite this finding, however, husband-wife agreement on those issues tends to be high. For example, Carol Underwood of Johns Hopkins University showed a high level of agreement among couples about attitudes towards family planning use. Ramadan Hamed of Egypt DHS Group reported a high level of husband-wife agreement with regard to having/not having another child.

Laila El-Zeini of the Social Research Center found that among couples who indicated that they were currently using family planning, only 50 percent said they had discussed family planning with their spouse. It is unlikely that one spouse was using family planning without the other's knowledge since both spouses indicated use of family planning. This raises questions about the validity of the question "have you discussed family planning with your spouse". Respondents may have had an understanding of the concept of "discussing" that is different from that of researchers. For example, a casual conversation or a joke with the husband about using family planning may be considered a form of discussion by some respondents but not others. 
Education was shown to be an important predictor of increased husband-wife communication. El-Zeni found discussion of family planning to be higher among younger couples and those with more education. Fatma El-Zanaty of the Egypt DHS Group also found that husband-wife communication tends to be higher among better educated couples. In her study it was mentioned that women with better education reportedly have more say in household decisions.

According to the studies discussion of family planning among couples is associated with better husband-wife relations. Underwood found discussion of family planning to be associated with more correct perception by women of their husband's stance regarding family planning use. In El-Zeini's study husband-wife communication was associated with higher levels of agreement on family planning attitudes and childbearing as well as higher levels of contraceptive use.

All of the studies showed that the husband is the one who usually has the final say on household decisions. However, the studies showed interesting dynamics in case of husband-wife disagreement. Hamed's study showed that when the husband and wife disagreed about having another child the couple was more likely to continue discussing the matter than to follow the husband's opinion. El-Zeini showed that when husbands and wives disagreed about use of family planning, the wife's wishes were more likely to be followed, especially if she was the one who wanted to use family planning.

A similar discrepancy was reported by El-Zanaty who found that many women believe it is legitimate for a woman to use family planning without her husband's knowledge, especially if she has health problems. Interestingly, many husbands said they would eventually accept their wife's decision to use family planning even if they were not convinced.

The discrepancy between what respondents claim they do and what actually happens suggests some degree of "social desirability bias" in response to the question "who has the final say over use of family planning". Since in this society the husband is expected to be the dominant figure in the family and the wife is expected to obey, both husband and wife are likely to subscribe to this image especially in public e.g. in an interview, lest they would be labeled "deviant". In private the dynamics of husband-wife relations are more complex and often involve 
strategies on the part of women to "indirectly" gain their husbands' support/approval (Aida Seif Al-Dawla and her colleagues refer to those strategies as "women's wit over men").

Another methodological issue relates to the data collection technique used. The dynamics of interactions between husbands and wives are complex and involve a number of culturally bound behaviors. As such qualitative methods were indicated as better suited than structured quantitative methods to uncover these dynamics. However, a focus group discussion may not be the best avenue to collect this type of data for the "desirability bias" considerations mentioned above.

\section{Suggestions:}

- Husband-wife communication about FP/RH could be increased through mass media. Media messages should promote husband-wife communication on all household decisions.

- Training of health providers to help husbands and wives communicate better about reproductive health matters. Training should help providers resolve ethical dilemmas e.g. which side should the provider take in case of husband wife disagreement about a specific issue.

- Changes in the current set-up of family planning clinics to allow for the presence of husbands in the clinics with their wives. This could enhance better husbandwife communication as husbands will become more aware of the issues and of their wives' health needs.

- Studies are needed to understand the dynamics of husband-wife decisionmaking, especially strategies used to resolve disagreement. More culturally appropriate research techniques and questions need to be used for a better understanding of those dynamics. Concepts such as "discussion with spouse" need to be properly defined and explained to respondents to create a common understanding between researcher and respondent. Qualitative methods may be the best recourse for studying such culturally bound behaviors.

\section{MEN'S PERCEPTIONS OF SEXUALITY/ REPRODUCTIVE HEALTH}

Studies in this session examined some of the larger socio-cultural factors that contribute to men's limited and sometimes negative involvement in the reproductive health of their spouses. All three presenters critiqued family planning programs/service providers' focus on women in all matters related to family planning/reproductive health. Kamran Ali of Rochester University raised the same point that was highlighted by Greene and Biddlecom regarding the "problematic 
approach" to dealing with men. Family planning programs as well as researchers have shown an interest in men because they realized that women are seldom the primary decision-makers on issues related to fertility and/or use of family planning. Programs tend to blame men for hindering their spouses' use of contraception. Ali Kamran argues that this approach to involving men is still deficient as it fails to acknowledge the influence of other family members or friends on the couple's reproductive decisions. It also fails to take account of the broader socio-economic factors e.g. unemployment, illiteracy, poverty that are in part responsible for the reproductive behaviors of both men and women.

Aida Seif Al-Dawla of the New Woman Research Center also took a critical stand regarding current approaches to involving men. She argues that positive husband involvement in reproductive health of their spouses will not be achieved by having men use condoms or accompany their wives to family planning clinics. Male involvement in reproductive health should address larger issues of power, control, and self-image. Researchers and program managers need to understand the reasons why men hold the attitudes that they have towards women and towards their own involvement in reproductive health. Such attitudes are to a large extent a result of men's concerns/ misconceptions about their own sexuality or that of the other sex. She suggests that the male image that has been prescribed by society (to be strong, masculine, rational) has placed a tremendous pressure on men to act in ways that are often inconsistent with the concept of male involvement. Seif Al-Dawla agrees with Ali that socio-economic problems tend to exacerbate men's feelings of insecurity about their manhood and hence result in further attempts to control women. It is important that men's perceptions of their own sexuality, including their fears and concerns be examined and addressed before any meaningful "male involvement" can be expected.

The third presentation by Abdel-Moneim Farag of Al-Azhar University provided the medical profession's standpoint on involving husbands in matters related to reproductive health. He presented a study that examined the content of the Ob/Gyn medical notes that are used by $4^{\text {th }}$ year medical students in Egypt based on the assumption that these notes play a major role in constructing physicians' perceptions of reproductive health and eventually their practice of medicine. 
According to Farag, currently used notes make very little, if any, reference to involving husbands in the health of their spouses. For example, under management of RTIs there is no mention of abstinence from sex or of husband referral for treatment. He argues that given this type of medical training it is unlikely that future physicians in Egypt will be aware of the role of husbands or that they will make any efforts to involve them in the health care of their spouses.

There was general agreement among participants that socio- cultural factors are largely responsible for men's limited involvement in reproductive health of their spouses. These social and cultural factors need to be addressed as part of any intervention to increase male involvement.

\section{Suggestions:}

- Improving the reproductive health of men and women can not be achieved without an overall improvement in the social and economic conditions of the people.

- Male and female reproductive health activists need to engage in an open dialogue to resolve the conflict between the "male image" and "male involvement in the health of their spouses". Men's concerns about their sexuality and that of their spouses should be addressed. The perceptions of policy-makers, health care providers, medical educators and the general public about masculinity/femininity and gender roles should be examined and addressed.

- $\mathrm{Ob} / \mathrm{Gyn}$ training for undergraduates needs to highlight the role of men in the health of their spouses. Senior physicians can set an example for residents and interns by involving the husbands of Ob/Gyn patients, whenever appropriate. 
Concepts of male involvement can also be included in the evaluation of medical students e.g. in the final exam.

- Community attitudes about male involvement and gender equality could be addressed through grass root interventions. Efforts to change attitudes about gender roles should start as early as childhood. Parents should treat their sons and daughters equally and should instill in their children the values of gender equality. Those values of gender equality should also be highlighted in school curricula.

\section{HUSBANDS AS PARTNERS IN REPRODUCTIVE HEALTH}

Husbands' involvement in reproductive health requires an understanding of the role of husbands in the reproductive health of their spouses as well as men's reproductive health needs. The studies from this seminar examined different aspects of husband involvement in reproductive health. Three were descriptive studies that examined husbands' knowledge, attitudes and practices in relation to the reproductive health of their spouses. The fourth was an intervention study that examined the effects of counseling husbands on postabortion patients' recovery and use of contraception.

It was clear from the presentations that husbands' knowledge about reproductive health matters is quite limited. Sarah Loza of SPAAC found husbands' knowledge about the complications that may occur during pregnancy, delivery or postpartum to be incomplete. Similar findings about knowledge of husbands were reported by Ferial Abdel-Kader of CDC. Mohamed Naguib of Cairo University reported a limited knowledge on the part of husbands with regard to male methods of contraception. Awareness of the condom is somewhat higher than that of other methods that require husband cooperation, namely withdrawal, safe period or male sterilization. In fact, none of the respondents in his study mentioned male sterilization.

Husbands may be willing to get involved in certain aspects of reproductive health but not others. Husbands are more willing to get involved in those aspects that do not pose a "violation" to the social image of being a male. According to Loza, during pregnancy husbands tend to provide substantial emotional support to their wives and buy them "nutritious" food. Husbands do not attend the delivery with 
their wives, but they make sure to be available to provide logistic support in case of emergency.

Abdel-Kader reported that husbands were likely to take their children to the doctor and to visit the child's school to find out about his/her performance. However, husbands were less likely to help their wives with housework except if the wife is sick. Naguib reported that the majority of husbands do not think it is necessary to share the responsibility of family planning use with their wives.

Very little is known about the impact of husband involvement on the health of their spouses. The study presented by Nahla Abdel-Tawab of the Population Council described an intervention for counseling the husbands of postabortion patients. The intervention included health education type of messages to husbands of postabortion patients about the patient's medical condition, her recovery and return to fertility. The study findings showed that providing information to husbands was associated with more positive involvement in their spouse's recovery. Also, husband involvement was found to be associated with improved physical and emotional recovery for the patient as well as greater likelihood to use contraception.

Besides highlighting the positive effects of husband involvement, the study raised a number of issues related to involving husbands in reproductive health services of their spouses. Involving husbands could pose a risk to some patients (e.g. patients who terminated a pregnancy without the knowledge of their husbands). The study also raised the point that involving husbands could result in undermining women's autonomy and in reinforcing men's control over women. The study also pointed out some of the service characteristics (e.g. lay-out, hospital regulations) that interfere with husbands' presence in hospitals/clinics with their wives.

\section{Suggestions:}

- Programs should include husbands in reproductive health services for their spouses. The awareness of policy-makers about the importance of involving husbands should be raised. Health care providers should receive training so as to be better able to include husbands in treatment regimens for their spouses. The need for interventions to improve the quality of counseling for husbands/couples was highlighted.

- Women's privacy and autonomy rights should not be compromised as a result of involving their husbands. Women should be consulted before involving their 
husbands in their health care. Providing information to the husbands should not become a substitute for giving counseling to the women.

- Another ethical issue relates to the impact of providing services for men on reproductive health services for women. Providing services for men should not undermine quality of services for women e.g. by making providers less available to provide services for women or by making women who go to those facilities uncomfortable due to the presence of men.

- Husband involvement is a multi-dimensional concept. This concept needs to be operationalized and valid indicators for its measurement need to be developed.

- Future research should assess men's needs for reproductive health services. Included in this topic are issues of access, acceptability, and men's health care needs.

- Research is also needed on men's attitudes and sources of knowledge / influence about their involvement in reproductive health services for women.

- Research should also examine women's attitudes about involving their husbands in matters related to their own health and about areas that they wish/do not wish their husbands to be involved.

- Research should assess the training needs of service providers with regard to providing services for men and to working with couples as opposed to women alone.

- There is a need for operations research to test feasibility and effectiveness of interventions designed to promote husbands' involvement in women's reproductive health issues. Different models of providing services e.g. husband and wife together versus separately, should be tested.

\section{THE MALE YOUTH / ADOLESCENT}

The seminar included only two studies that examined reproductive health needs of Egyptian youth, which reflects the paucity of research in this area. The first study by Saad Zaghlool Amin of the Cairo Demographic Center and his colleagues found that youth knowledge about reproductive health is quite limited. The media is the main source of information for both sexes. Friends are the second source of information for men while for women it is the family. Men do not prefer to obtain information from their parents because they feel shy about discussing those subjects with them. 
The presentation by Fatma El-Zanaty of the Egypt DHS group revealed a substantial level of sexual activity among university students in Egypt (25.5\% of male students and $3.2 \%$ of female students reported ever having sex). Among students who ever had sex, about one third reported having had sex with more than one sex partner. Also, one third of respondents reported not using a condom in the most recent sexual encounter. It is noteworthy that about half of the students who reported ever having sex, indicated that they changed their sexual behavior after hearing about AIDS.

Many participants were alarmed by the above findings. Others argued that the percentages of students who actually had sex may be even higher than those reported by El-Zanaty. Some students may have been shy to admit to having such relations because of the social stigma around this issue. Participants agreed that the social environment in Egypt and the social taboos around discussions of sex / reproduction are largely responsible for the lack of knowledge about reproductive health among Egyptian youth, which places youth at great risk of a number of sexual misconceptions, dysfunctions and possibly STDs.

\section{Suggestions:}

- There is a need for interventions to educate youth about sexuality and reproductive health. High school curricula should include more information about reproductive functions and STDs. NGOs could play a role in reaching school drop-outs and working adolescents.

- Interventions targeted towards parents are called for to encourage them to communicate with their children about reproductive health matters and/or encourage their children to seek information about those issue, especially before marriage.

- Service providers need to be trained on providing services, including counseling for youth. Training should help providers overcome any personal biases against providing services for youth.

- Interventions may be needed to raise awareness of policy-makers about the reproductive health needs of youth. Senior officials at the Ministries of Youth and Sports, Education, Higher Education and Scientific Research, and religious leaders should be provided with reliable and policy relevant findings.

- Given the sensitive nature of the issue, reproductive health services for youth / adolescents need to be provided in a culturally acceptable manner. In the meantime confidentiality of adolescents / youth who are seeking services should 
be protected. A telephone hotline similar to the one that is currently in operation to answer questions about HIV/ AIDS was suggested as one of the procedures to protect confidentiality in seeking information.

- The need for more research on youth: their sexual knowledge and practices, information and service needs and appropriate channels for reaching them. Participants, however, pointed out some of the difficulties around obtaining permits to conduct this type of studies due to the sensitivity of the topic. Use of self-administered questionnaires was also suggested as a substitute to the interviewer- administered questionnaire to avoid normative responses about sexual behaviors.

\section{FUTURE DIRECTIONS IN PROGRAMS AND RESEARCH INVOLVING MEN}

Maali Guemei of AVSC described the global initiative of "Men as Partners in Reproductive Health" and reported on the "Men As Partners" workshop that was organized by AVSC in Mombasa, Kenya in 1997. Workshop participants from Egypt identified the following areas of male involvement as priorities for Egypt: (1) training of service providers on involving husbands in matters related to the health of their spouses, (2) research to better understand the reproductive health needs of men and their role in the health of their spouses, (3) improving reproductive health services for men, (4) a gender-sensitive social climate that supports women's rights and equality between men and women.

Hassan El-Gebaly of the Ministry of Health and Population (and also one of the participants in the MAP workshop) described recent efforts by the Systems Development Project (SDP) to increase male involvement in reproductive health. The MOHP, through the SDP, has taken steps to increase awareness of its staff about the importance of involving men in matters related to the reproductive health of their spouses. SDP standards of practice as well as training curricula are under revision to take into account the role of husbands in family planning. SDP is also revising clients' medical record forms to include information about husbands.

\section{CONCLUDING REMARKS}

The seminar on male involvement in reproductive health provided an opportunity for researchers, program managers and policy-makers to exchange information and to share their perspectives with regard to involving men in reproductive health matters. There was a general agreement that involving men in 
reproductive health is important for improving the health and well-being of both men and women. Men should no longer be seen as "obstacles" to improved health of their spouses but as full fledged partners who are have their own needs and concerns and who are also understanding of their spouses' needs.

Increasing men's involvement in reproductive health poses several challenges to researchers, program managers and policy-makers. Men's involvement or their lack of involvement in matters related to reproductive health is largely a result of strongly held values about gender roles and expectations. Attempts to increase male involvement will inevitably have to address and challenge those strongly-held beliefs.

Services for men should be integrated within the current reproductive health services. However, program managers need to think of creative ways for including men without undermining the quality of services for women or violating women's rights to autonomy and privacy. An equally challenging issue relates to providing culturally sensitive services for youth without encroaching on their rights to confidentiality.

The role of research in increasing men's involvement in reproductive health matters can not be overemphasized. Discussions that took place during the seminar identified a number of research gaps that need to be addressed for a better understanding of men's and women's needs as well as best ways to address those needs. Since research that involves men is a relatively new domain, it was helpful for researchers to address some of the ethical and methodological issues that are involved in this type of research. It is hoped that this seminar will contribute to the conduct of more studies on men that are both ethically and methodologically sound that could be used by policy-makers in developing better reproductive health services for men and women. 


\section{REFERENCES}

Greene, M. \& Biddlecom, A. 1997. Absent and Problematic Men: Demographic Accounts of Male Reproductive Roles. New York, the Population Council. 


\section{SEMINAR AGENDA}

Research on Male Involvement in Reproductive Health in Egypt: Summary of Findings and Future Directions

May 4-5, 1998

Alexandria, Egypt

\section{Seminar objectives:}

1. Present findings of current studies on male involvement in reproductive health care programs in Egypt.

2. Identify policy and program management implications of the maleoriented research

3. Identify methodological and ethical issues related to conducting research that involves men

4. Identify themes for future operations research on male involvement in reproductive health in Egypt.

DAY 1 (May $\left.4^{\text {th }}, 1998\right)$

\begin{tabular}{|c|c|}
\hline 8:30 - 9:00 & Late registration \\
\hline 9:00 - 9:30 & $\begin{array}{l}\text { Opening remarks } \\
\text { Dale Huntington, Population Council } \\
\text { Mahmoud Khedr, Ministry of Health and Population } \\
\text { Richard Martin, USAID, Cairo }\end{array}$ \\
\hline $9: 30-11: 30$ & $\begin{array}{l}\text { Session 1: Husband-wife communication about } \\
\text { family planning } \\
\text { Moderator: Sawsan Fahmy, Alexandria University }\end{array}$ \\
\hline $9: 30-9: 55$ & $\begin{array}{l}\text { Intra-couple gender constructs in Egypt: shared or } \\
\text { contested terrain? } \\
\text { Carol Underwood, JHU/PCS }\end{array}$ \\
\hline $9: 55-10: 20$ & $\begin{array}{l}\text { Husbands' role in family planning decision-making } \\
\text { Ramadan Hamed, DHS Group }\end{array}$ \\
\hline $10: 20-10: 30$ & BREAK \\
\hline $10: 30-10: 55$ & $\begin{array}{l}\text { Family planning in Egypt between wives and husbands } \\
\text { Laila El-Zeini, Social Research Center }\end{array}$ \\
\hline
\end{tabular}


$10: 55-11: 20$

$11: 20-11: 30$

$11: 30-1: 30$

$11: 30-11: 55$

$11: 55-12: 20$

$12: 20-12: 45$

$12: 45-1: 00$

$1: 00-2: 00$

$2: 00-4: 00$

$2: 00-2: 25$

$2: 25-2: 50$

$2: 50-3: 00$

$3: 00-3: 25$

$3: 25-3: 50$
Household decision-making and communication between couples

Fatma El-Zanaty, DHS Group

\section{Concluding comments}

Session 2: $\quad$ Men's perceptions of sexuality/reproductive health

Moderator: Shawky El-Akabawy, Al-Azhar University

Planning the family: Some thoughts on research among Egyptian men and women

Kamran Ali, Rochester University

Reproductive health: a women's agenda

Aida Seif El-Dawla, New Woman Group

According to the medical texts: Role of men in women's reproductive health matters

Abdel-Moneim Farag, Al-Azhar University

\section{Concluding comments}

\section{LUNCH}

Session 3: Husbands as partners in reproductive health Moderator: Laila Kafafi, Family Health International

Husbands' knowledge, attitudes and practices in relation to maternal health

Sarah Loza, Social Planning, Analysis \& Administration Consultants

Attitudes of husbands towards a number of reproductive health issues

Mohamed Naguib, Cairo University

BREAK

Male responsibility in reproductive health

Ferial Abdel-Kader, Cairo Demographic Center

Effects of husband involvement on postabortion patients recovery and use of contraception in Egypt

Nahla Abdel-Tawab, Population Council

Concluding comments 
Day 2 (May $5^{\text {th }}, 1998$ )

\begin{tabular}{|c|c|}
\hline $9: 00-10: 00$ & $\begin{array}{l}\text { Session 4: The Male Youth } \\
\text { Moderator: Salha Awad, Institute for Research and } \\
\text { Training on Family Planning }\end{array}$ \\
\hline 9:00 - 9:25 & $\begin{array}{l}\text { Knowledge and attitudes of Egyptian youth about } \\
\text { reproductive health } \\
\text { Saad Zaghlool Amin, Cairo Demographic Center }\end{array}$ \\
\hline $9: 25-9: 50$ & $\begin{array}{l}\text { Behavioral research among university students } \\
\text { Fatma El-Zanaty, DHS Group }\end{array}$ \\
\hline $9: 50-10: 00$ & Concluding comments \\
\hline $10: 00-10: 15$ & Break \\
\hline $10: 15-12: 45$ & $\begin{array}{l}\text { Session 5: Future Directions in Programs and } \\
\text { Research Involving Men } \\
\text { Moderator: Laila Nawar, Population Council }\end{array}$ \\
\hline $10: 15-10: 30$ & $\begin{array}{l}\text { Men As Partners (MAP) Initiative } \\
\text { Maaly EI Guemie, AVSC Int'l }\end{array}$ \\
\hline $10: 30-10: 45$ & $\begin{array}{l}\text { An overview of MOHP efforts in the area of male } \\
\text { involvement } \\
\text { Hassan El-Gebaly, MOHP }\end{array}$ \\
\hline $10: 45-12: 00$ & Breakaway group discussions \\
\hline $12: 00-12: 15$ & Pause \\
\hline $12: 15-12: 45$ & Group presentations \\
\hline $12: 45-1: 00$ & $\begin{array}{l}\text { Closing statements } \\
\text { Nahla Abdel-Tawab, Population Council }\end{array}$ \\
\hline 1:00 - 2:30 & Lunch and departure \\
\hline
\end{tabular}




\section{PARTICIPANT LIST \\ Research on Male Involvement in Reproductive Health in Egypt: Summary of Findings and Future Directions}

May 4-5, 1998

Alexandria, Egypt

Al-Azhar University

Shawky El-Akabawi

Abdel-Moneim Farag

Alexandria University

Emad Darweesh

Mona Mortada

Sanaa Abdel Aziz

Sawsan Fahmy

Seham Ragheb

Sunny Sallam

Assiut University

Sayed Abdel-Hamid

\section{AVSC}

Maali Guemei

Mawaheb El-Mouelhy

Cairo Demographic Center

Ferial Abdel-Kader

Saad Zaghlool Amin

General Ezzat El-Shishiny

Cairo University

Mohamed Naguib

Hala Youssef

Clinical Services Improvement

Project

Mohamed Edrees

Sawsan El Sheikh

Demographic and Health Survey

Group

Fatma El-Zanaty

Hamed Ramadan
Egyptian Family Planning

Association

Abdel-Salam Hassan

Sanaa El-Kassass

Egyptian Fertility Care Society

Naglaa El-Nahal

Family Health International

Laila Kafafi

Ford Foundation

Jocelyn DeJong

Institute for Research \& Training on

Family Planning

Salha Awad

Mansoura University

Hesham Shaalan

Ministry of Health and Population

Mahmoud Khedr

Amira Qassem

Hassan El-Gebali

Mostafa Fahmy

Hassan Nabih

Samir Mansour

Saber Lawendy

MotherCare Project

Ali Abdel-Meguid

National Commission for Population and Development

Mahassen Hassanein 
National Population Council (RMU)

Adel Hakim

Netherlands Embassy

Marieke Boot

New Woman Research Center

Aida Seif El-Dawla

Policy Project

Mona Khalifa

Population Council

Dale Huntington

Laila Nawar

Nahla Abdel-Tawab

Sahar Hegazi

Susan Lee

Ubaidur Rob

Saraswati Raju

Kamran Ali

Population Project Consortium

Scott Moreland

Ron Hess

Carol Underwood
Press

Bahira Mokhtar

Nawal Moustafa

Regional Center for Training

Safaa El-Baz

Social Planning Analysis \&

Administration Consultants

Sarah Loza

Social Research Center

Laila El-Zeini

State Information Services / IEC

Center

Samy Sultan

Afaf Zaghlool

Nafissa Mostafa

USAID

Richard Martin

Ayman Abdel-Mohsen

Nahed Matta

Karin Ringheim 


\section{Abstracts of Presented Studies}

\section{Session One: Husband Wife Communication about Family Planning}

\section{Carol Underwood. 1997. Intra-couple Gender Constructs in Egypt: Shared or Contested Terrain? \\ Population Project Consortium, CAPMAS, SIS/IEC}

An underlying assumption of the analysis reported in this presentation is that the individual's construction of gender will be highly correlated with perceptions of family planning or, put more simply that family planning attitudes are subsumed within the broader construct of gender. We also expect to find a relationship between these perceptions and fertility behavior, as in previous studies. This study attempts to take this research one step further by examining not only the relationship between women's gender constructs and family planning attitudes, but to take into account their husbands' perceptions of gender and contraceptive practice in relationship to the couples' fertility outcomes as well as to compare intra-couple levels of agreement. In the qualitative phase of this study, commonly held beliefs and values of different groups within the population were elicited through 36 focus-group discussions and 30 in-depth interviews. Psychographic statements derived from the qualitative phase constituted the core of the questionnaire, administered in a nationally representative, household-based survey of 2,086 randomly selected couples in May 1996. The predominant finding is that couples tend to share gender constructs, whether those constructs are narrowly defined or broadly understood. A minority, albeit a substantial minority in a few instances, of couples registered at opposite ends of the continuum with respect to their level of agreement with a given statement; in short, their gender construct lie in contested terrain. Still, the major difference lies not between women and the men to whom they are married, but at regional level. The findings presented in this paper further demonstrate that gender constructs have independent effect on perceptions of contraceptive practice and methods as well as on fertility outcomes even after controlling for age, education, place of residence, and work status. The analysis also shows that husband's and wives' gender constructs and family planning attitudes are generally correlated, and that husband's perceptions of gender contribute significantly to our understanding of the couple's fertility behavior. This suggests that the primary audience segmentation need not be men and women, but rather regionallevel segmentation with programs and messages developed to respond to regional needs and concerns.

\section{Ramadan Hamed Mohamed. 1996-1997. Husbands' Role in Family Planning Decision- making. \\ National Population Council and Macro Int.}

This paper is assigned for presenting some findings of the Egypt In-depth Study (EIS) of the reasons for nonuse of family planning concerning the husband role in family planning decision-making. The EIS was carried out to collect information on the factors which are contributing to the low level of use in Upper Egypt despite the significant demand among women to control childbearing. The EIS was a panel study, involving two rounds of followup interviews with respondents from Assuit and Souhag. Another important feature of the EIS is the mix of qualitative and quantitative methodologies used to obtain data. The first 
phase of the study included Focus Group Discussions with women and men while the second phase included panel interviews. Round 1 of the panel study was conducted with women and Round 2 included women and husbands. The findings of the EIS indicated that couple communication with regard to family planning is less common than discussion of childbearing preferences. For the majority of women, the husband's agreement is crucial to the use of family planning. However, in cases of disagreement negotiations often take place between couples. The findings of the EIS should be instrumental in identifying new directions for family planning program in Egypt in general and especially in Upper Egypt. The family planning program must convince men of the benefits of family planning. Information and motivation campaigns must address men's concerns about family planning use. Moreover, there should be active efforts to promote couples' communication regarding their childbearing goals.

\section{Laila El Zeini. 1997. Family Planning in Egypt between Wives and Husbands,}

Although unmet need is a usually defined with reference to women it is a couple's issue. The role played by husbands in the decision to use family planning and in the choice of contraceptive methods is particularly relevant to the study of unmet need for family planning. The main question addressed by the present study is how inter-spousal communication and decision-making practices are related to the use of family planning and the choice of the method used. The study uses data from the 1992 Demographic and Health Survey in which a special husband questionnaire was added in one third of the household sample. The sample for the present study includes 2,086 couples. The analysis is based on comparable information collected from wives and husbands on fertility preference, communication, decision-making process and on knowledge, attitudes and practice of contraceptives. The study showed that only a minority of couples had ever discussed family planning with each other and fewer couples had ever discussed the number of children they desired. Couples were less likely to have an unmet need for family planning when they had a higher level of communication and when they both wanted to stop childbearing. When spouses disagreed however, use of contraceptives was higher when it was the wife and not the husband who did not want more children. Couples who showed a better level of communication had also a more favorable attitude towards male methods. Communication between spouses is therefore very important for achieving agreement and to minimize unmet need for family planning.

Interventions are needed to increase husband-wife communication about family planning and to increase husband involvement in family planning.

\section{Fatma Hassan El Zanaty. 1997. Household Decision-making and Communication between Couples.}

El Zanaty and Associates and the World Bank

The action research for population project is a beneficiary assessment (BA) which was conducted in Egypt for the first time in 1997. The main objective of this research was to gain a thorough understanding of major factors affecting decision-making dynamics and motivation for having smaller families. This will lead to design projects, which can help increase the demand of family planning and strengthen the norms towards a small family size. The research consisted of focus group discussions (FGDs), In-Depth Interviews (IDI), Participant observation and Database Questionnaire. The FGDs included household decision- 
making and communication between couples and barriers to adopting family planning methods, and community communication patterns. The in-depth interviews were held with individuals who would have a great influence on a couple's decision concerning family planning like mothers, mothers-in-law, and religious leaders. The study was implemented in five governorates in Upper Egypt, namely Fayoum, Beni Sweif, Menia, Qena and Aswan. The data from FGDs showed that couples communicate together concerning all family matters. The majority of men mentioned that the husband is responsible for the whole family, he is the leader and he is the decision-maker. However, in situations of disagreement about family planning use husbands are likely to accommodate their wife's wishes to use family planning. These results can be used in designing special programs to address men concerning information about FP, the concept of contraception for men, and the importance of face to face communication in changing men's attitudes about controlling women ...etc.

\title{
Session Two: Men's Perception of Sexuality / Reproductive Health
}

\author{
Kamran Asdar Ali. 1994. Planning the Family: Some Thoughts on Research on \\ Egyptian Men and Women. \\ Population Council and The Johns Hopkins University
}

In the last decade, the Egyptian State in collaboration with international donor agencies has embarked on an ambitious population control program. In this process the association of reproduction and fertility with femaleness effectively perpetuates the domestic/public dichotomy and splits social analysis into female/male spheres. To accentuate the acceptance and use of contraceptive methods by women, internationally sponsored family planning programs now also focus on male partners within the household to increase their involvement in decision making. The paper will seek to evaluate the endeavor to enhance male involvement in family planning decisions in Egypt by the state and international development agencies as a continuation of the historical effort to modernize the Egyptian poor.

\section{Aida Seif El Dawla. Reproductive Health: A Women's Agenda. New Woman Research Center}

Reproductive health issues and gender issues cannot be successfully addressed unless there is an attempt to understand the perspectives of both actors, women and men. For the two "sexes" reproductive health issues touch on issues of power, control, self-image, sense of security or threat. The presentation will review the results of two studies: The first is the Egyptian component of the Reproductive Rights Research Action group, a cross country research that addressed women's perceptions of men's attitudes are based on a real or imagined understanding of what men actually want. The second study is a field research on violence against women carried out by the New Woman Research center and El Nadim center for the Management and Rehabilitation of Victims of Violence. Again the research aimed at investigating the prevalence of violence against women in a random sample of 500 women, their perception and understanding and attitude towards this violence. The research also involved them as actors in society. The presentation will also draw on some of the figures of the Egyptian Demographic Health Survey (EDHS 1995). It will shortly refer to some 
reactions that similar presentations have been met with in several conferences and seminars organized and attended by health professionals, advocates, planners etc., and will attempt to read those reactions from a gender perspective. It will suggest that the approach and practice of reproductive health and rights issues are exercised on two levels: a socially determined, overt and public level where the discourse is dominated by socially accepted norms, and another more real and down to earth level, where those issues are being addressed and manipulated to the best interest possible of those who are socially oppressed: the women. It will argue that those two levels do not only exist among the "grassroots" but also among advocates and actors in the field of reproductive rights and health issues. The presentation recommends that male involvement in reproductive health and rights issues should equally take place on all levels involved, starting from the decision-makers to the consumers, and that a serious and patient dialogue between women's organizations and health planners and decision-makers is a necessary starting step in this process.

\section{Aida Seif El Dawla and Abdel Moneim Farag. 1998. According to the Texts: What is the Role of Men in Women's Reproductive Health Matters Reproductive Health Working Group (HWG) and Al-Azhar University}

The present study provides a social and gender analysis of study texts and aids used in teaching OB/GYN for $5^{\text {th }}$ year medical students from Al-Azhar University (men's section). The textual analysis is part of a larger pilot project which looked at the role of medical education in constructing physicians perceptions of women's health. For this component of the study, some students were asked to provide an exhaustive list of all the texts and aids, including audio and audio-visual aids to study obstetrics and gynecology. These piles of materials were reviewed with an eye on their social and gender content. The findings suggest a clear neglect of men in the reproductive health matters of women. The study findings showed hardly any reference to the role of husband in chapters on pregnancy, delivery, post-partum care, contraception or RTIs. The study interprets these findings and their impact on the knowledge and performance of young physicians.

\section{Session 3: Husbands as Partners in Reproductive Health}

\section{Sarah Loza. 1997. Husbands' Knowledge, Attitudes and Practices in Relation to Maternal Health \\ MotherCare, Ministry of Health and Population, and SPAAC}

This study utilizes data collected in 1997 from Luxor and Aswan Governorates to determine barriers and positive forces at the community level that influence service utilization from the perspective of mothers as service users and their influentials. Husbands were considered as part of the mother influentials. Twelve focus groups discussions (FGDs) were administered to husbands of mothers of children under two in rural and urban areas of the five Aswan districts plus Luxor. The transcripts of the 12 husband FGDs were reanalyzed for this study with the objective of understanding how husbands perceive their roles in support of their wives' maternal health during pregnancy, delivery and postpartum. It also investigates husbands' knowledge level of signs of complications and their attitudes and views on existing 
obstetric services. The findings indicate that husbands have a very important supportive role during pregnancy. Their role during delivery tends to be minor as compared to pregnancy. However, they are financially responsible for costs and they stand by for logistic support in times of emergency. During postpartum, their role is minimal. They only ensure the availability of the needed food and beverage items needed to strengthen the mother and support lactation. Husbands are aware of a number of signs of complications during pregnancy, delivery and postpartum. That knowledge is incomplete in terms of coverage and in terms of depth, however. They are also aware of pros and cons of utilization of public hospitals versus private physicians and clinics for maternity services. Such knowledge is useful for prompt emergency decisions to use existing obstetric services. These findings indicate that husbands do care for healthy pregnancies and healthy pregnancy outcomes. Even though they are convinced that these are "women issues" and women know more about it, yet they do share and carry out essential responsibilities that complement the roles of women of the family and neighbors. As such they should be included in counseling to reduce overall maternal morbidity and mortality.

\section{Mohamed Naguib A. Fattah. 1998. Attitudes of Husbands Towards a Number of Reproductive Health Issues.}

Egyptian Family Planning Association (EFPA) and International Planned Parenthood Federation (IPPF)

This presentation is a part of an operation research entitled "Integrated Reproductive Health Services in EC Centers". The research was conducted by EFPA and funded by IPPF. The main objective of the presentation is to focus on the attitudes of husbands toward some of reproductive health $(\mathrm{RH})$ issues. One of the immediate objectives of this research is to identify the needs of clients and their husbands for RH services. In this research, a situation analysis technique was used for different groups: clients, husbands, youth and staff workers. The total sample size of husbands interviewed is 130 and that represents half from the total clients. The data was collected from six centers coverings five governorates (Ismalia / Dakhalia / Qaliobia / Gharbia and Behera) by using structured questionnaire. The questionnaire included the following parts, (background, FP \& early marriage, and awareness of husbands RH services). The study showed that husbands' awareness of RH issues is very modest: husbands' knew very little about male methods of contraception and the majority were unwilling to share the responsibility of using a family planning method or to visit a family planning center.

\section{Hesham Makhlouf and Ferial Abdel Kader. 1997. Male Responsibility in Reproductive Health.}

Cairo Demographic Center (CDC)

In spite of several national wide surveys which has been conducted in Egypt over the past fifteen years, there is still a lack of information about male's responsibilities in reproductive health (RH), family planning (FP) and sexual health (SH). It was decided to use the DHS of 1995 sample of undertaking the survey. A systematic selection of one half of the total population sampling units (PSU) of DHS was considered. The eligible husbands refer to those husbands of the eligible women who were interviewed in the DHS. The number of the 
completed questionnaires was 3596 distributed among all governorates excluding the frontiers. A special questionnaire was designed to fulfill the survey objectives. Results

regarding the husband's responsibility were found to be as follows: More than half of the husbands (57\%) visit their children schools but only $37 \%$ of them help their children in study. About two thirds of the husbands take the child to the doctor with or without the mother. A high proportion of husbands do not help their wives with housework. Husbands' knowledge about the health problems that could occur during pregnancy, delivery or after delivery was somewhat limited. Also, the ideal number of children was slightly higher for husbands than for wives. It is recommended that the government, NGOs, and the religious and community leaders would support IE\&C efforts to encourage the equal participation of men and women in all areas of family responsibility, including reproductive health care, child rearing and housework.

\section{Nahla Abdel Tawab, Dale Huntington, Ezzeldin O. Hassan, Hala Youssef, Laila Nawar. 1997. Effects of Husband Involvement on Postabortion Patients' Recovery and Use of Contraception in Egypt. Population Council ANE OR/TA Project and the Egyptian Fertility Care Society}

Despite the documented role of husbands as decision-makers in reproductive health matters, very little has been done to formally involve husbands in matters related to the health of their wives, particularly in relation to postabortion care. The present study examines the effects of counseling the husbands of postabortion patients on patients' recovery and subsequent use of contraception in Egypt. The study was conducted in six hospitals in Menia governorate.

Consenting postabortion patients who were admitted to the study hospitals were randomly assigned to an intervention or a control group. Husbands of patients in the intervention group received information about their wives' medical condition, their recovery and use of contraception. Husbands of patients in the control group did not receive such counseling. Follow-up interviews were conducted with the above one-month after discharge from the hospital to determine level of husband involvement, patients' physical and emotional recovery and use of contraception. A total of 293 postabortion patients completed the study. The study findings showed that counseling of husbands was associated with higher levels of instrumental, emotional and family planning support by the husband. The study also showed increased husband involvement to be associated with improved patient recovery and a substantial increase in the likelihood of contraceptive use. Based on the study findings it is recommended that counseling of husbands should become an integral component of the medical services provided to postabortion patients in Egypt.

\section{Session 4: The Male Youth}

Hisham Makhlouf and Saad Zagloul Amin. 1995. Inquiring about the Knowledge of Egyptian Youth on Reproductive Health Cairo Demographic Center (CDC), Egyptian Family Planning Association (EFPA)

This study was conducted, after the 1994 ICPD, to provide information on recent situation of Egyptian youth in knowledge and attitudes towards RH elements, to be used by EFPA to conduct programs to enlighten Youth on R.H. issues and risks. A random sample of 3200 of both sexes aged (15-24) were interviewed at secondary schools, universities and institutions 
in urban and rural areas of lower and Upper Egypt. They were asked about their knowledge, sources of knowledge and attitudes towards issues such as early marriage, timing of first conception, female circumcision. Most youth know about AIDS but they do not know

anything about other sexually transmitted diseases such as gonorrhea. About $23 \%$ of males and $40 \%$ of females do not know the parts of the reproductive system of the two sexes. The mass media is the main source of knowledge followed by family for females and friends for males. The family is the preferred source of information for women before puberty, before marriage and after marriage while for men preferred sources include friends, books, media and family planning centers at the three stages of life. About $64 \%$ of males and $42 \%$ of females support female circumcision because they believe that this operation is related to religion. It is recommended that future programs should emphasize providing complete information and adjusting negative attitudes of youth.

\section{Fatma Hassan El-Zanaty. 1996. Behavioral Research among University Students. MEDTEC and Family Health International}

Despite present low rates of HIV infection in Egypt, several potential routes exist to introduce further cases of HIV infection to Egypt. Intravenous drug use is an increasingly important problem in both rich and poor classes. This study aimed at determining knowledge, attitudes and beliefs about HIV/STDs among university students (18-24 years) in greater Cairo, assess their risk perception for HIV/STDs, examine underlying factors or motivations for behavior which places them at risk, and identify strategies that influence behavior change. The study included qualitative and quantitative data collection procedures. The qualitative data included conducting FGDs with male and female students. The quantitative data collection included 1250 completed interviews with students (males and females) in four universities namely; Cairo, Ain Shams, Al-Azhar and American University. The results showed that $16.5 \%$ of the students had sexual intercourse ever before, with older students and male students reporting higher percentages. A substantial proportion of students who reported ever having sex had more than one sexual partner. Also, about one third of students did not use condom in the last sexual encounter. AIDS prevention programs should raise people's awareness (particularly adolescents and youth) of the possible ways of AIDS transmission, namely, unprotected sexual intercourse, blood transmission and use of contaminated injections and surgical instruments. Also, adolescents and youth should be encouraged to abstain from having sexual intercourse outside the context of marriage. 